No. 2, vol. xxxiv., of The Astrophysical Journal, Dr. Joel Stebbins discusses the probability of there being a number of readily detectable eclipsing variables among those stars known to be short-period spectroscopic binaries. Such stars must offer the phenomena of mutual eclipse to some parts of the universe, and Dr. Stebbins establishes the probability that a very fair proportion will present more or less partial eclipses to the earth; as a class, that is, they offer greater probability of the discovery of eclipsing variables than do the bulk of the stars. Not only that, but their periods can be more or less determined from their spectroscopic elements, and so the times of maximum light-variations suggested. Such periods would be the most favourable for observation, and with the selenium photometer Dr. Stebbins considers that for stars of magnitude 2.0 and brighter a 0.10 magnitude variation may be considered conspicuous, so that very small eclipses might become evident in properly timed observations.

To test his proposition, Dr. Stebbins made observations of $\beta$ Aurigæ and $\delta$ Orionis, and found that both were eclipsing variables. The work on the latter is not yet complete, but its extreme light-range is not far from o. 10 magnitude.

In the case of $\beta$ Aurigæ, a number of consecutive observations indicated no change, but on October 23, I910, the selenium photometer showed the magnitude to be 0.07 fainter than before. From a number of observations, fully discussed in the same number of the journal, $\mathrm{Dr}$. Stebbins finds that the total range is 0.087 magnitude, of which 0.076 is due to eclipses and $0.0 \mathrm{II}$ is due to ellipticity of figure of the two components. The times of light-minimum are apparently in exact accordance with the times predicted from Baker's spectroscopic elements. It would also appear that the surface-intensities of the components are many times greater than that of the sun.

Cometary Phenomena.-From Dr. K. Bohlin we have received an abstract from the Naturwissenschaftlichen Rundschau in which he reviews our present knowledge of cometary phenomena. In the first part systems of comets are dealt with, and in the last of five well-defined systems, we find comet rgroa classed with I89o IV. and I 907 I. In dealing with the light, extent, and structure of comets, there is little that is new to record; and in the chapter on spectra the latest results are not mentioned, although they replace much that preceded them. The section discussing the tails of comets, and the strange fluctuations in the streams of matter forming them, is interesting, and is illustrated by some reproductions from photographs.

Observations and Catalogues of Nebulf.-Now that the subject of the classification and distribution of nebulæ is to the fore, Dr. Bauschinger's publication in vol. iv., part i., of the Annalen der Kaiserlichen UniversitätsSternwarte in Strassburg, of the Strassburg observations and catalogue, will prove a weicome addition to the literature dealing with the subject.

The publication consists of three parts, in the first of which Dr. Wirtz discusses his observations of nebulæ made with the $49-\mathrm{cm}$. refractor during the period April, I902, to March, igio. The general methods of observation are described, and then the results tabulated; special micrometer measures of the stars in the Omega and Dumbell nebulæ were made, and the results are shown on two charts.

The second part of the present publication contains a general catalogue of the nebulæ observed at Strassburg from I881 until Igro, and gives the various designations, the positions (I900.0), and brief descriptions of the physical features of 1257 nebula; the catalogue has been compiled by Dr. Wirtz, who writes the introduction, wherein he points out that it is the outcome of the work initiated by Winnecke in 1872 . The final part of the publication consists of a most interesting comparison, by Dr. Wirtz, of the Strassburg results with those of other nebulæ observers.

A New Observatory in Africa.-From No. 45 rg of the Astronomische Nachrichten we learn that the French Geographical Society charged M. Jarry Desloges with the erection of a more or less temporary observatory on the "Hautes Plateaux" of northern Africa. Extensive and arduous researches as to the "seeing" at various places over a wide region at an altitude of I IOo metres or more have been made, and now an observatory is in course of erection.

\section{RECENT SOIL INVESTIGATIONS}

I $\mathrm{T}$ is well known that the United States Bureau of Soils does not attach the same importance to a chemical analysis of the soil as is usual elsewhere. The argument adopted is that all soils contain the same rock minerals, and therefore the soil solution from which plants derive their nourishment must be identical in composition, so far as mineral plant food is concerned, in all cases. But inasmuch as the aqueous extracts of different soils show the same kind of differences towards plants as the soils themselves, it follows, if the original hypothesis is true, that the infertility of the poor soils must be due to some toxic organic substance. Search is therefore being made for substances of this nature, and during the progress of the experiments numerous interesting fields are opening up. Evidence has, for example, been obtained which is considered to prove that the roots of growing plants, and particularly the root hairs, possess an extracellular oxidising power; this power is greatest in fertile soils, and is diminished in certain infertile soils. The oxidation is attributed mainly, if not entirely, to the activity of a peroxidase produced by the roots. Messrs. Schreiner and Reed, the authors of this paper, also consider that soil itself can effect oxidations closely analogous to those of an oxidase, although, in their view, the process is mainly non-enzymotic.

Another publication, also from the Bureau of Soils; gives the results of Messrs. Robinson and McCaughey's investigations on the colours of soils, which they trace to organic matter and to ferric oxide. All varieties of colour, from white to yellow, red, brown, and black, are thus derived, the darker colours indicating, as a rule, the better agricultural conditions.

In addition to the research work going on, the Bureau of Soils is also engaged in a soil survey of the States, the results of which are issued in the form of circulars dealing with particular soil types. The basis of the survey is the mechanical analysis of the soil; but the officer in charge makes full local investigations, so that the report always takes account of the agricultural conditions. Among the reports issued, so far, are those dealing with the Portsmouth sandy loam, the Sassafras silt loam, the Norfolk fine sandy loam, and the Norfolk fine sand. In a general introductory circular Dr. Whitney describes in non-technical language the kind of examination that is made in the laboratory, and the limitations to which soil analysis is subjected. The account is very interesting, and will be found useful to others engaged in this work.

Messrs. Hart and Peterson, of the Wisconsin Agricultural Experiment Station, have recently published their work on the sulphur requirements of farm crops. Some years ago $\mathrm{Mr}$. Dymond directed attention to the problem here, and showed that the supply of sulphates was not always adequate to the needs of the crop. A similar conclusion is reached by Messrs. Hart and Peterson, and they suggest that, in order to meet the losses due to drainage and cropping, it will be necessary for permanent fertility to supply sulphates to the soil.

The biochemical significance of phosphorus is discussed by Miss Caird in a paper read before the Royal Society of Victoria, a reprint of which was recently to hand. The low phosphorus content of the Australian soils is well known; it appears, also, that Australian native grasses have a markedly lower phosphorus content than European, and that the wood of Australian trees is lower in phosphates than European trees. Acclimatised European grasses contain more phosphorus than the native sorts, but less than the same kinds grown in Europe. Finally, it is pointed out that the loss of phosphorus from Victorian grass lands by export of their products is considerable, and must be made good.

NO. 2 I86, VOL. 87] 